\title{
Turismo de prática desportiva: um segmento do mercado do turismo desportivo
}

\author{
Pedro Guedes de Carvalho ${ }^{1}$ \\ Rui Lourenço 1,2
}

\section{RESUMO}

O Turismo Desportivo representa o corpo de conhecimento e o conjunto de práticas onde as áreas do turismo e do desporto se tornam interdependentes. Esta área de sobreposição evidenciase a dois níveis que se poderão chamar de Turismo de Espectáculo Desportivo e Turismo de Prática desportiva. De acordo com Pigeassou ${ }^{(9)}$, os fundamentos do turismo desportivo não são os mesmos que se utilizam na classificação de actividades desportivas.

Neste artigo procura-se dar um contributo teórico para a compreensão do Segmento de mercado do Turismo de Prática Desportiva através de uma análise da tipologia de comportamento dos seus clientes, clarificando as motivações dos mesmos e mostrando a importância que essa proposta pode ter no desenvolvimento do destino turístico.

Alguns resultados de um trabalho experimental realizado são também apresentados.

Palavras-chave: turismo, desporto, turismo desportivo, turismo de prática desportiva, turismo de espectáculo desportivo
${ }^{1}$ Centro de Estudos em Desporto, Saúde e Desenvolvimento Humano (CIDESD)

Universidade da Beira Interior

Portugal

2 Técnico Superior nas Termas de Monfortinho

Portugal

ABSTRACT

Sport practice tourism: a segment of sport tourism market

Sport Tourism represents the knowledge and the group of practices where Sport and Tourism became interdependent. This overlapping area turns clearly at two levels that might be named by Sport Tourism Spectacle and Sport Tourism Practice.

According to Pigeassou ${ }^{(9)}$ the foundations of sport tourism do not consist purely of classifying sport tourism activities using categories employed in sport activities.

In this article we provide a theoretical framework for the understanding of the market segment in Sport Tourism Practice, looking at their client behaviour typology, their motivations and high lightening the role this framework plays on the tourist destiny development. Furthermore we present some empirical results of a seminal experimental design.

Key-words: tourism, sport, sport tourism, sport tourism practice, sport tourism spectacle 


\section{INTRODUÇÃO}

Nos últimos 30 anos a evolução tecnológica e social transformou de forma fantástica o modo como a maioria das pessoas vêem o tempo e a vida. Se há algumas décadas atrás era impensável para a generalidade da população viajar pelo simples prazer de conhecer sítios novos, hoje isso é banal para muita gente, de tal modo que a viagem turística já se transformou em algo mais do que conhecer sítios novos. Neste contexto o Turismo vive uma fase de profunda transformação. Mais do que sítios diferentes ou oportunidades de descanso, as pessoas viajam cada vez mais à procura de novas experiências, novas vivências associadas a diversas práticas activas. Como um dos pontos mais marcantes nesta transformação podemos destacar a passagem de um turismo inactivo, em que o objectivo era "desligar" e isolarmo-nos do mundo, para um turismo activo onde o objectivo é também viver nos limites o contexto da viagem e retirar desta a maior quantidade e a melhor qualidade de vivências e experiências marcantes.

O desporto, actividade onde o Homem experimenta os seus limites, está inserido nas mesmas dinâmicas da sociedade contemporânea, experimentando também uma fase de crescimento e de mutação. Assume novas formas, novos contextos e novos valores, onde para além da competição com os outros, as pessoas procuram para si evasão, saúde e novas vivências. O desporto no seu todo representa actualmente um dos mais fascinantes e relevantes fenómenos sociais; Manuel Sérgio refere mesmo que "o Desporto é o fenómeno cultural de maior magia no mundo contemporâneo"(14).

Para além de se desenvolverem de forma individualizada, o turismo e o desporto foram-se desenvolvendo ao longo dos tempos de forma sistémica, com sinergias e áreas de sobreposição. Este aspecto torna-se especialmente evidente nas últimas décadas do século XX, dando origem ao que se passou a designar na literatura por Turismo Desportivo. Para além da prática desportiva assume também especial relevância o espectáculo desportivo; por isso o Turismo Desportivo apresenta duas tipologias especialmente relevantes, uma associada ao espectáculo desportivo (TED) e uma segunda associada à prática desportiva (TPD).

É objectivo deste artigo contribuir para a com- preensão desta relação e, consequentemente, estabelecer com maior rigor um quadro conceptual que permita potenciar o desenvolvimento sustentável no segmento de mercado do Turismo de Prática Desportiva (TPD), seja enquanto motivação principal de viagem ou como complemento de outras motivações turísticas.

\section{DESPORTO E TURISMO - UMA EVOLUÇÃO PARALELA}

Nas suas formas contemporâneas pode dizer-se que Desporto e Turismo tiveram origem na revolução industrial e mantêm, desde essa época, uma evolução individualizada mas com um paralelismo muito interessante.

Foram idênticos os factores, os tempos e os contextos sociais que representaram pontos de mudança e de desenvolvimento, podendo destacar-se 4 factores que tiveram um papel fundamental para a relevância que estes dois fenómenos representam hoje na sociedade:

\footnotetext{
Figura 1. llustração do percurso dos fenómenos desporto e turismo ao longo do tempo
}

A concentração das populações em torno dos centros urbanos;

O aumento da duração do tempo de lazer;

$\mathrm{O}$ aumento do poder de compra; e

O desenvolvimento dos meios de transporte. 
Com tantos pontos em comum este percurso acabaria por se cruzar como seria de esperar. Como se ilustra na Figura 1, o Turismo e o Desporto passam a ter actividades, contextos e práticas comuns aos dois sectores de actividade a partir de determinada época. Estes campos comuns representam uma zona onde as duas actividades se sobrepõem; a este espaço de sobreposição ou de "intercepção" como refere Pigeassou ${ }^{(9)}$, chama-se actualmente Turismo Desportivo. Kurtzman e Zauhar(5) afirmam mesmo que "os pontos de contacto entre o desporto e o turismo tem aumentado drasticamente".

Embora se possa considerar que as relações entre Turismo e Desporto se tenham iniciado mais cedo, o turismo desportivo tal como o conhecemos hoje tem a sua origem em meados do século XX, estando em grande medida associado ao "surgimento dos desportos de Inverno nos Alpes" (8). No entanto, a expressão "turismo desportivo" surge apenas na década de 70 em França (8).

Partindo deste quadro, É nosso entender que, para se estudar o turismo desportivo como instrumento potenciador do desenvolvimento sustentado, se torna necessário clarificar os seus dois conceitos constituintes - o turismo e o desporto.

\section{Desporto}

No âmbito da Carta Europeia do Desporto o

Conselho da Europa define desporto como:

"Todas as formas de actividades físicas que, através de uma participação organizada ou não, têm por objectivo a expressão ou o melhoramento da condição física e psíquica, o desenvolvimento das relações sociais ou a obtenção de resultados na competição a todos os níveis"(13).

De acordo com esta definição e tendo como quadro de referência a "Motricidade Humana" incluir no conceito de desporto todas as suas novas formas. Estas são cada vez menos formalizadas, geradas em função de um contexto específico e submetendo-se muitas vezes a uma lógica comercial de produto.

Esta posição está em concordância com autores como Standeven e De Knop que defendem que uma definição larga de desporto permite "aumentar o significado das ligações entre turismo e desporto"(15).

Devemos realçar também que o desporto se assume à escala global como um excelente espectáculo² capaz de mobilizar multidões e de fidelizar uma imensa quantidade de espectadores, por um lado através da presença ao vivo, mas especialmente através do acompanhamento à distância e muitas vezes em simultâneo.

Com base nestes pressupostos considerar-se-á como desportistas, não só o praticante desportivo mas também o espectador desportivo, sendo estes dois grupos os principais clientes actuais do mercado Desporto.

\section{Turismo}

A Organização Mundial do Turismo (OMT), agência especializada das Nações Unidas (ONU) dedicada ao turismo com sede em Madrid define Turismo como: "O conjunto das actividades desenvolvidas por pessoas durante as viagens e estadas em locais fora do seu ambiente habitual por um período consecutivo que não ultrapasse um ano, por motivos de lazer, de negócios e outros"(6).

Como cliente do mercado turístico, a OMT considera o Visitante, que será qualquer pessoa que viaja para qualquer lugar fora do seu ambiente habitual por menos de 12 meses consecutivos e cujo motivo principal da visita não seja o de exercer uma actividade remunerada no local visitado.

A OMT distingue ainda entre Turista que será o visitante que permanece pelo menos uma noite no local visitado e Visitante do dia, a pessoa que não permanece pelo menos uma noite.

Este tipo de definições são extremamente úteis do ponto de vista estatístico e quantitativo, bem como para definir um quadro de referência objectivo.

O Turismo é no entanto um fenómeno extremamente complexo, lato e interdisciplinar e ter-se-á que se considerar como parte integrante da actividade turística os meios que permitem a viagem, as actividades e os serviços turísticos numa lógica sistémica e de interacção com os outros sectores de actividade.

\section{ENQUADRAMENTO CONCEPTUAL: O TURISMO DESPORTIVO}

A relevância das áreas de sobreposição que se referiram tem aumentado de tal forma que na actualidade podemos falar da existência consolidada de Turismo Desportivo quer do ponto de vista conceptual, quer pela sua relevância de mercado. Pigeassou(9) considera que o contributo económico deste segmento de 
mercado do turismo "tem crescido fortemente nas últimas décadas".

O Turismo Desportivo representa assim o corpo de conhecimento e o conjunto de práticas onde as áreas do turismo e do desporto se tornam interdependentes, merecendo alguma especialização no seu estudo. A Figura 2 ilustra esta relação.

Podemos dizer que existe um conjunto de actividades que são simultaneamente turísticas e desportivas, carecendo portanto das abordagens pluridisciplinares entre o turismo e desporto. Pigeassou, BuiXuan e Gleyse(8) referem que "clarificar a noção não significa necessariamente que o fenómeno definido como turismo desportivo não possa ser analisado através de metodologias usadas no estudo do turismo e do desporto"

Figura 2. Sobreposição do Turismo e do Desporto

É nossa opinião que o turismo desportivo não emerge de qualquer ruptura com o desporto ou com o turismo, mas sim de uma abordagem metodológica pluridisciplinar entre estes dois fenómenos. Não existe uma prática que tenha deixado de ser desportiva, ou deixado de ser turística, para passar a ser turístico-desportiva. O que se passa é que o fenómeno desporto cresceu num sentido que fez com que o desporto tivesse necessidade de recorrer aos serviços e aos conhecimentos do turismo. O inverso também acontece, o turismo cresceu num sentido que torna útil a utilização dos serviços e dos conhecimentos do desporto no âmbito da actividade turística.

Pigeassou, Bui-Xuan e Gleyse( ${ }^{(8)}$ consideram que o turismo desportivo enquanto disciplina se encontra ainda numa "fase pré-paradigmática". Existe assim, no actual contexto do desenvolvimento do turismo desportivo, a necessidade de fomentar uma relação muito próxima entre os técnicos de desporto e os técnicos de turismo, de modo a que a reunião destes dois "saber-fazer" permita potenciar ao máximo o desenvolvimento tanto do ponto de vista conceptual, como da compreensão das dinâmicas do segmento de mercado do turismo desportivo.

Várias instituições e autores têm apresentado contributos relevantes para a compreensão do conceito de turismo desportivo. De entre os vários contributos destaca-se por exemplo a OMT e autores como Standeven e De Knop na sua obra intitulada "Sport Tourism"(15), Cunha no seu trabalho "Introdução ao Turismo"(2), onde o turismo desportivo é apresentado como um tipo de turismo ${ }^{3}$. Também apresentam especial relevo alguns artigos publicados no Journal of Sport Tourism ou no Cahier Éspaces, dos quais se podem destacar "Epistemológical Issues on Sport Tourism: Challenge For a New Scientific Field" de Pigeassou, Bui-Xuan e Gleyse(8, 11), "Sport and Tourism: A Conceptual Framework" de Gammon e Robinson(4) ou "A Wave in Time - The Sports Tourism Phenomena” de Kurtzman e Zauhar(5), entre outros.

Apesar de os vários autores apresentarem diferentes perspectivas de análise, a necessidade de associação entre turismo e desporto é consensual na análise do conceito de turismo desportivo.

Assumindo esta óbvia sobreposição entre turismo e desporto torna-se necessário, para que se considere um indivíduo como turista desportivo, considerar que esse individuo tem que ser turista e simultaneamente participar numa actividade desportiva ou desenvolvida em contexto desportivo.

Assim, é possível definir quatro premissas que é necessário verificar para se considerar um qualquer indivíduo como turista desportivo; as primeiras três decorrentes dos conceitos de turismo e de turista referido nos ponto 2.2 e a última premissa implicando a participação em actividades ou contextos associados ao desporto, cujo o âmbito foi definido no ponto 2.1 .

Temos assim que considerar:

1 - Que a pessoa realize uma viagem para fora do seu ambiente habitual e que permaneça pelo menos uma noite no local visitado (menos de uma noite 
será o Visitante Desportivo do dia ${ }^{4}$;

2 - Que esta viagem não tenha carácter definitivo, considerando normalmente que ela não deva exceder os 12 meses;

3 - Que esta viagem não tenha como motivação principal exercer uma actividade remunerada; e 4 - Que o viajante participe durante a viagem ou a estada, numa actividade ou contexto desportivo.

Se a associação entre turismo e desporto era consensual na bibliografia consultada, no que se refere às diferentes actividades e contextos que se podem considerar dentro do universo do turismo desportivo, as opiniões são um pouco mais diversas. Ainda assim, dois pontos são quase consensuais: (i) a Inclusão da prática desportiva e (ii) a assistência enquanto espectador.

De realçar uma quase unanimidade em considerar como turismo desportivo para além das actividades desportivas praticadas pelos turistas, também as actividades desportivas a que o turista assiste ou é espectador. Diversos autores utilizam uma terminologia que considera a prática desportiva como participação activa e a assistência a um espectáculo desportivo como participação passiva.

Para além das actividades direccionadas para a prática e para a assistência desportiva, existe um conjunto de outros aspectos que embora menos consensuais, ou abordados de diferentes perspectivas, são referidos na literatura e podem ser considerados como zonas de sobreposição entre o turismo e o desporto.

No entanto, é nossa opinião que o conjunto de actividades desportivas em que participem turistas, seja enquanto praticantes ou espectadores, representam o maior relevo no fenómeno Turismo Desportivo. As outras formas de turismo desportivo que abordaremos resumidamente no ponto 3.3 deverão assim ter um peso residual e pontual enquanto zonas de sobreposição entre as áreas do desporto e do turismo. Este dado carece ainda assim de uma análise mais aprofundada de indicadores como a quantidade de turistas envolvidos em cada um dos tipos de turismo desportivo ou os volumes de negócios associados.

A participação de turistas em actividades ou contextos desportivos pode agrupar-se na seguinte tipologia:

1 - Turismo de prática desportiva (TPD);

2 - Turismo de espectáculo desportivo (TED);

3 - Outros contextos turístico-desportivos.
Em conclusão e como sistematização do fenómeno turismo desportivo, apresenta-se a Figura 3 que ilustra os diferentes tipos de turismo desportivo.

Figura 3. Principais tipos de Turismo Desportivo

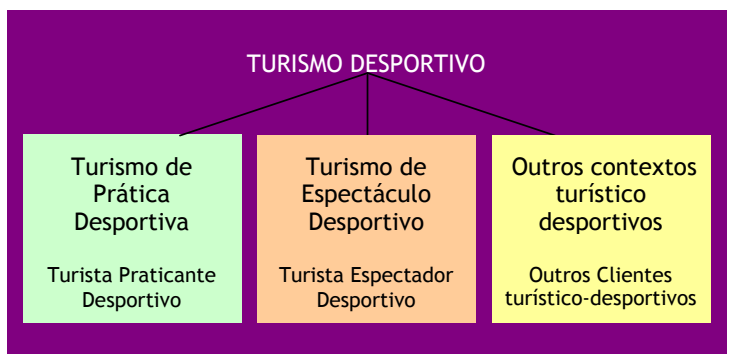

A importância desta clarificação é a de que a cada tipo definido podemos associar também um tipo de cliente, o que tem diferentes implicações no marketing e estratégia de desenvolvimento económico. Assim definidos os conceitos, importa realçar ainda que o turismo desportivo e cada um dos seus tipos, não se resumem aos seus clientes. Para além dos clientes, é necessário considerar as dinâmicas entre todos os intervenientes no fenómeno. Na Figura 4, que apresentaremos aquando da análise do mercado do turismo de prática desportiva, podemos verificar como em qualquer outro mercado, que para além dos clientes/consumidores é necessário considerar os produtores, os distribuidores e os facilitadores. No entanto é nossa opinião que a organização de todas as dinâmicas deve começar pela análise rigorosa dos clientes-tipo que poderão viabilizar e potenciar um determinado mercado.

\section{Turismo de prática desportiva}

Relativamente ao turismo de prática desportiva este pode definir-se como o Conjunto de actividades desportivas em que participem turistas enquanto praticantes. Podemos considerar a pessoa com este tipo de participação no desporto como o turista praticante desportivo que, por sua vez se poderá definir como aquele Turista que, durante a sua viagem, pratica uma qualquer actividade desportiva, independentemente da motivação principal da viagem.

Pigeassou ${ }^{(9)}$ chama e esta família de relações entre o turismo e o desporto a "prática de actividades físicas 
e/ou desportivas" ou "Turismo desportivo de acção" onde a "actividade física é um iniciador e um intermediário da experiência" que se vive.

$\mathrm{Na}$ estrutura de relações de "sinergia" entre turismo e desporto, Robinson e Gammon(12) não distinguem a prática desportiva como segmento do turismo desportivo, mas referem-se ao turismo desportivo como a "análise dos indivíduos e/ou grupos de pessoas que participam activamente ou passivamente em desporto competitivo ou recreativo" podendo considerar-se a "participação activa" como a prática desportiva.

De uma forma menos atenta poder-se-ia ter a tentação de definir turismo de prática desportiva como o turismo em que a principal motivação de viagem fosse a participação numa qualquer actividade desportiva enquanto praticante. No entanto uma análise mais aprofundada permite perceber que este tipo de turismo representa apenas uma parte dos turistas praticantes desportivos. Com efeito, também as pessoas que embora tenham outra motivação de viagem, como por exemplo o turismo de sol e mar ou o turismo em espaço rural, podem vir a praticar uma actividade desportiva. Independentemente da motivação da viagem, a prática desportiva por parte dos turistas representa um campo de sobreposição entre o turismo e o desporto. Este aspecto será desenvolvido na secção 4.

\section{Turismo de espectáculo desportivo}

Relativamente ao turismo de espectáculo desportivo, este poderá definir-se como o conjunto de actividades desportivas de que usufruam os turistas enquanto espectadores considerando-se a pessoa com este tipo de participação no turismo desportivo como o turista espectador desportivo. Este poderá assim definir-se como o turista que, durante a sua viagem, assiste a um qualquer espectáculo ou evento desportivo, independentemente da motivação principal da viagem. Pigeassou ${ }^{(9)}$ chama e esta família de relações entre o turismo e o desporto a "participação em eventos ou exibições focadas no desporto" ou "Turismo desportivo de eventos", em que "uma proximidade sensorial e emocional com a situação real é essencial". Robinson e Gammon(12) na mesma análise referida no sub-capítulo 3.1 referem-se à "participação passiva" podendo considerar-se esta como a assistência a espectáculos desportivos.
Assim considerado, o espectáculo desportivo tem-se desenvolvido de forma exponencial ao longo das últimas décadas, em parte devido ao desenvolvimento mediatizado de competições a nível global, consequência do desenvolvimento dos meios de transporte e comunicação de larga escala ocorrido a partir de meados do século passado.

Os modelos competitivos bastante atractivos vieram fomentar a assistência ao vivo às competições desportivas (exemplos disso: os Jogos Olímpicos, o Campeonato do Mundo de Futebol, Campeonato do Mundo de Formula 1, Voltas nacionais em ciclismo,...) tornando-os numa nova forma de actividade económica de elevada relevância nas economias dos países. Tem-se assim uma enorme quantidade de pessoas que se deslocam tendo como objectivo principal assistir a espectáculos desportivos ou que, estando de férias com qualquer outra motivação, acabam por assistir a espectáculos desportivos que se realizam no mesmo destino turístico.

Este mercado assume assim um relevo muito significativo, não só pela capacidade de atracção de turistas de forma directa, mas também como forma de promoção dando visibilidade a um determinado destino ou contexto turístico. A título de exemplo poderíamos referir o Euro 2004 realizado em Portugal e que para além das receitas directas que proporcionou, também contribuiu de forma muito interessante para a promoção de país no exterior.

O TED assume assim diversas características que permitem análises distintas e muito úteis para a compreensão do fenómeno turismo desportivo, analises essas que serão aprofundadas noutros artigos futuros.

\section{Outras formas de turismo desportivo}

Pigeassou( ${ }^{(9)}$ refere quatro tipos de práticas sociais que associam turismo e desporto e que são, para além do "turismo desportivo de acção" e do "turismo desportivo de evento", o "turismo desportivo de cultura" e o "turismo desportivo de envolvimento". O turismo desportivo de cultura refere-se a um carácter mais cognitivo da cultura desportiva que pode estar associado a um sentido de história desportiva, de curiosidade intelectual ou de veneração. O turismo desportivo de envolvimento refere-se às situações inerentes ao mundo do desporto, nomeadamente às inú- 
meras possibilidade de viagem turística associadas à administração desportiva ou ao treino. Por exemplo o "staff de uma competição" ou os "workshops de formação desportiva complementares".

Para além de considerarem que a relação entre turismo e desporto pode ser "participativa" ou "não participativa”, Kurtzman e Zauhar(5) utilizam uma terminologia mais prática, identificando cinco categorias de turismo desportivo: as "atracções de turismo desportivo", os "resorts de turismo desportivo", os "cruzeiros de turismo desportivo", as "viagens de turismo desportivo" e os "eventos de turismo desportivo".

Em nossa opinião existe um conjunto de relações entre turismo e desporto que vão para além do TPD e do TED sendo estas tipologias muito variadas e apresentando cada uma delas aspectos muito específicos e que importa analisar caso a caso.

Sem nos alongarmos nesta discussão, deixamos alguns pontos que poderão servir de ponto de partida para uma análise mais aprofundada:

- algumas destas relações podem não implicar clientes de turismo desportivo (por exemplo: os estágios pré-competitivos das equipas de desporto profissional têm normalmente um efeito muito superior ao nível da promoção turística do que do desenvolvimento de serviços de turismo desportivo); - algumas destas relações podem estar muito próximas de outros tipos de turismo (por exemplo: do turismo cultural no caso dos museus ou exposições com motivos desportivos);

- algumas destas relações representam nichos muito específicos e cujo a interpretação dificilmente pode ser transposta para outros contextos.

\section{O MERCADO DE TURISMO DE PRÁTICA DESPORTIVA}

Na presente secção analisa-se o mercado do TPD, isto é, o conjunto de actividades desportivas em que participem turistas enquanto praticantes, abordando a forma como estas se organizam e atendendo ainda às dinâmicas que geram para poderem ser exploradas numa lógica de mercado.

No trabalho "Reinventando o Turismo em Portugal"(1) publicado pela Confederação do Turismo Português/SaER é sugerido o modelo apresentado na Figura 4 para sintetizar a Organização Actual da Indústria do Turismo.
Figura 4. Organização actual da indústria do turismo

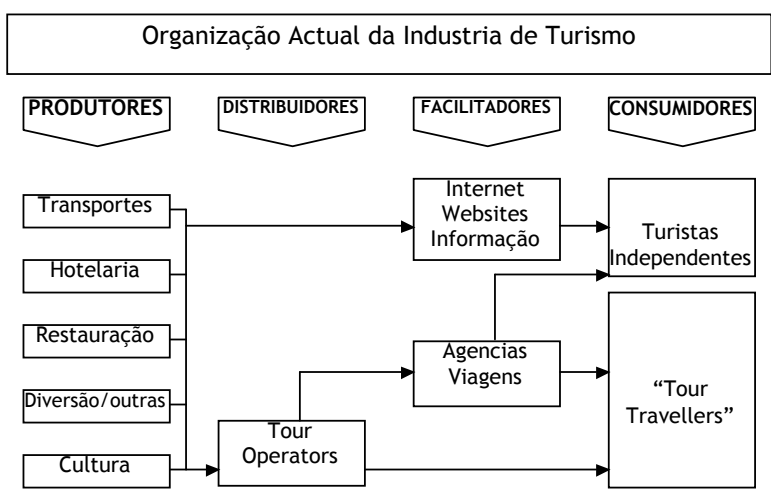

Fonte: Adaptado de CTP[1]

Neste modelo podem distinguir-se, como noutros mercados, quatro tipos de agentes intervenientes na indústria do turismo: os Produtores, os Distribuidores, os Facilitadores e os Consumidores. Este modelo não faz referência a um tipo de agentes que parece muito relevante para o desenvolvimento da Indústria do Turismo e que se poderiam designar de "Planificadores», isto é, os agentes públicos e não públicos que contribuem para o estudo do fenómeno e para a definição de estratégias globais de um determinado sector ou tipo de agentes ou ainda para a construção de um verdadeiro destino turístico. Será o caso por exemplo dos organismos públicos de promoção turística quer a nível nacional, regional ou local; das associações empresariais representantes de uma determinada região ou sector; das escolas e institutos responsáveis pelo estudo do turismo, etc. Na perspectiva económica e de marketing são as necessidades e motivações dos consumidores que definem quais os melhores produtos e quais os melhores canais que os Produtores, os

Distribuidores e os Facilitadores devem utilizar para chegar aos Consumidores/Clientes.

Cabe a quem planifica uma actividade tornar coerente a adequação entre estas necessidades e os objectivos de mais largo prazo como exige qualquer actividade económica moderna (preocupações com o ambiente e a sustentabilidade de uma região, país ou mesmo do Planeta).

Vamos de seguida caracterizar os turistas praticantes desportivos e distinguir os principais tipos que se podem considerar. 


\section{Turismo de prática desportiva - os consumidores}

Os Turistas Praticantes Desportivos, isto é, os consumidores de TPD, podem ser analisados sob duas perspectivas: (i) a da viagem turística e toda a logística que a torna possível e (ii) a da prática desportiva e tudo o que exige a sua organização e realização. Relativamente à viagem turística, o modelo de indústria do turismo apresentado distingue dois tipos de turistas, os Turistas Independentes e os "Tour Travellers", exigindo a consideração de dois tipos de atitudes determinantes da procura de viagem turística. No TPD podem encontrar-se estes dois tipos de turistas, dependendo muito do tipo de destino turístico, do tipo de actividade desportiva escolhida e até da personalidade e das preferências do próprio turista pelo que é importante realçar outros aspectos para além da forma de planeamento da viagem.

Pigeassou, Bui-Xuan e Gleyse(8) afirmam que "o meio desportivo é a primeira característica e o mais importante elemento no turismo desportivo" No mesmo raciocínio também os aspectos associados à prática desportiva constituem o principal elemento diferenciador relativamente aos outros tipos de turismo desportivo ou outro.

\section{Dois tipos de turistas praticantes desportivos}

A prática desportiva pelos turistas pode constituir-se como uma motivação de viagem ou como um complemento dessa viagem. Robinson e Gammon(12) num artigo dedicado à questão dos motivos primários e secundários na estrutura do turismo desportivo e referindo-se genericamente ao turismo desportivo $^{5}$ salientam que este pode dividir-se entre os que "viajam em primeiro lugar pelo desporto" e os que consideram o desporto numa perspectiva secundária. Aquilo que consideramos novo em relação ao trabalho de Pigeassou( ${ }^{(9)}$ na nossa abordagem é que, na realidade, uma viagem turística tem normalmente uma motivação comportamental principal associada; no que diz respeito ao TPD esta motivação principal da viagem permite distinguir dois tipos de consumidores ou dois tipos de turista praticante desportivo aos quais vamos chamar de Entusiasta e Esporádico, sendo que:

- Entusiasta será o turista que se desloca para um qualquer destino tendo como motivação principal a prática de uma actividade desportiva específica e
- Esporádico será o turista que pratica uma qualquer actividade desportiva durante a sua viagem, mas em que a prática desportiva não é a motivação principal da viagem.

E é esta diferença que permite clarificar o papel da oferta turística na captação de novos clientes do segundo grupo.

Por exemplo, um turista que se desloca com a motivação de fazer termas e acaba por realizar um percurso pedestre que lhe é proposto pela equipa de animação das termas é também um TPD Esporádico. Consideremos por exemplo um turista que se desloca à Serra tendo como objectivo a realização de uma travessia a pé entre dois abrigos de montanha. Ele será um TPD Entusiasta, neste caso entusiasta do pedestrianismo.

Parecendo pouco relevante esta distinção, ela evidencia contudo a existência de dois tipos de turistas que, podendo utilizar a mesma actividade como meio de ocupação de uma parte do seu tempo dedicado ao turismo, confere à prática desportiva características claramente distintas do ponto de vista do marketing e, como tal, necessitam de ser abordados de forma diferenciada nos produtos/serviços que se lhes proponham.

Os produtores, distribuidores e facilitadores, bem como "os planificadores", que intervêm mercado das actividades de TPD podem ter a consciência da existência dos dois públicos completamente distintos a que se dirigem, o que implica que se saibam direccionar-se a cada um deles de forma eficiente, nomeadamente no que diz respeito às:

- Modalidades/actividades desportivas a propor; e - Estratégia a definir para cada destino turístico. Nesse sentido, a clarificação de conceitos aqui proposta tem um alcance importante no desenho de uma estratégia de desenvolvimento turístico com base em actividades desportivas.

Vários autores têm realçado estes dois tipos de comportamento dos turistas face à prática desportiva, embora usem terminologias distintas.

Robinson e Gammon(12) usam uma terminologia que considera "turismo desportivo" quando o desporto é a "principal motivação de viagem" e "desporto turístico" quando o "desporto é uma actividade secundária”. Por sua vez, Pereira(7) distingue entre uma "vertente eminentemente desportiva" e uma "vertente 
eminentemente turística" considerando que no primeiro "as pessoas se deslocam tendo como principal objectivo o desporto" e que no segundo "o sistema turístico é o motor do binómio", onde "a procura de práticas desportivas, por parte dos turistas, se centra essencialmente na óptica do lazer". Devemos ainda assim referir que embora estes dois autores considerem a prática desportiva, não a distinguem do espectáculo desportivo como segmentos significativamente distintos, considerando-os fenómenos integrados. No entanto eles reflectem diferentes atitudes comportamentais dos turistas face à prática desportiva. A nossa concepção diferencia-se da apresentada na literatura uma vez que encara a actividade desportiva como um potencial instrumento de acréscimo de valor e não apenas como uma mera actividade turística residual. Considerando que o turismo de prática desportiva representa um segmento do turismo desportivo com características suficientemente autónomas para justificar uma análise autónoma e considerando ainda que existem dois perfis de cliente claramente distintos, importa definir ferramentas que permitam aos técnicos que actuam no terreno intervir de forma eficiente.

Para o efeito sistematizam-se na Tabela 1 algumas semelhanças e diferenças entre o TPD Esporádico e o TPD Entusiasta, quanto às características/-actividades/decisões que nos parecem mais marcantes para caracterizar estes consumidores.

Para além da comparação decidiu-se agrupar os pontos que permitem distinguir entre os dois tipos em: 1 - Aspectos relacionados com o turismo e planeamento da viagem e

2 - Aspectos relacionados com a prática desportiva. O trabalho experimental que se fizer com base em indicadores objectivos para cada uma das dimensões definidas deverá permitir avaliar se esta hipótese de categorização proposta é a mais ajustada.

\section{Principais impactos do TPD no destino turístico}

Também podemos pensar o turismo de prática desportiva como elemento gerador de dinâmicas de sustentabilidade dos destinos turísticos. Não sendo ainda possível uma verificação experimental deste tema, sugerimos alguns efeitos que, em nossa opinião, se constituem como os mais relevantes e que devem ser alvo de análise.
Relativamente aos praticantes Entusiastas poderá considerar-se um efeito de "evento de prática desportiva» em que os turistas se deslocam a um destino com a motivação de participar num evento específico e um efeito de "visita regular" em que o que motiva a visita são as condições de referência aparentadas pelo destino turístico para a prática de uma actividade específica.

Relativamente aos praticantes Esporádicos terá especial relevo um efeito de "animação turística», isto é, de complemento e valorização de uma outra actividade turística principal.

Dado o diferente impacto económico que cada uma delas pode ter esta análise torna-se particularmente importante na definição de políticas municipais e de entidades diversas, uma vez que as autarquias, clubes e outras entidades têm uma enorme propensão para se empenharem e subsidiarem fortemente alguns eventos e actividades na crença de que ela são determinantes para a promoção territorial dos seus territórios. Ora pode não ser sempre esse o caso.

\section{SÍNTESE}

Muitos têm sido os autores que ao longo das últimas décadas têm procurado conceptualizar acerca do fenómeno Turismo Desportivo e da sua relevância económica e social, bem como, acerca do corpo de conhecimentos e do conjunto de práticas onde as áreas do Turismo e do desporto se tornam interdependentes.

Embora dentro da mesma relação de sobreposição entre turismo e desporto, o TPD apresenta, em termos de procura e consequentemente em termos de oferta, características bem distintas dos outros tipos de turismo desportivo. Pelo que importa analisar este segmento de forma substancialmente autónoma. Considerando o segmento do TPD, torna-se importante desenvolver ferramentas e perspectivas de análise do fenómeno que permitam tanto aos técnicos de desporto como aos de turismo intervir nesta área de forma mais eficiente.

Para afinar a operacionalização desta proposta definiram-se dois tipos de turistas praticantes desportivos, os entusiastas e os esporádicos, cuja principal distinção tem a ver com o comportamento e a motivação principal da viagem; característica esta que revela uma atitude completamente distinta dos potenciais clientes face 
Tabela 1. Comparação entre turistas praticantes desportivos Esporádicos e Entusiastas

\begin{tabular}{|c|c|c|c|}
\hline & Características/Actividades/Decisões & TPD Entusiasta & TPD Esporádico \\
\hline \multirow{2}{*}{ 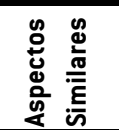 } & São turistas & Sim & Sim \\
\hline & Praticam desporto durante a viagem & Sim & Sim \\
\hline \multirow{4}{*}{ 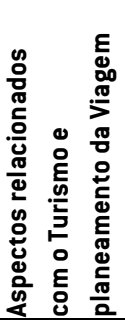 } & $\begin{array}{l}\text { Têm como motivação principal de viagem praticar } \\
\text { desporto }\end{array}$ & Sim & Não \\
\hline & $\begin{array}{l}\text { Planeiam a viagem em função do desporto que vão } \\
\text { realizar }\end{array}$ & Sim & Não \\
\hline & Decidem praticar desporto antes de iniciarem a viagem & Sim & Normalmente Não \\
\hline & $\begin{array}{l}\text { Percentagem do tempo de férias dedicado à prática da } \\
\text { actividade escolhida }\end{array}$ & Normalmente Alta & Normalmente Baixa \\
\hline \multirow{6}{*}{ 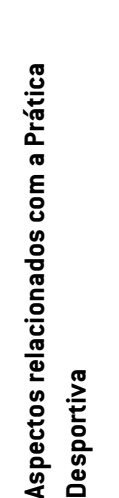 } & $\begin{array}{l}\text { Praticam com regularidade a actividade desportiva que } \\
\text { vão realizar nas férias }\end{array}$ & $\begin{array}{l}\text { Normalmente } \\
\text { Sim }\end{array}$ & Normalmente Não \\
\hline & $\begin{array}{l}\text { Equipamento individual necessário para a prática do } \\
\text { desporto que praticam em férias é }\end{array}$ & Normalmente Próprio & Normalmente Alugado \\
\hline & $\begin{array}{l}\text { As habilidades motoras exigidas para a prática da } \\
\text { actividade escolhida são }\end{array}$ & $\begin{array}{l}\text { Muitas vezes } \\
\text { Complexas }\end{array}$ & Normalmente Simples \\
\hline & 0 nível com que a actividade é Praticado é & $\begin{array}{l}\text { Intermédio ou } \\
\text { Avançado }\end{array}$ & $\begin{array}{l}\text { Normalmente de } \\
\text { Principiante }\end{array}$ \\
\hline & Podem estar disponíveis para adquirir aulas de & Aperfeiçoamento & Iniciação \\
\hline & $\begin{array}{l}\text { Nível de exigência em termos de condições e infra- } \\
\text { estruturas para a prática do desporto escolhido }\end{array}$ & Normalmente Elevado & $\begin{array}{l}\text { Baixo ou } \\
\text { Pouco Específico }\end{array}$ \\
\hline
\end{tabular}

à prática desportiva realizada no contexto turístico. Dentro de uma lógica global do destino turístico, as actividades/modalidades desportivas a propor, as suas formas de organização e de promoção devem considerar estas diferenças de atitudes, potenciando ao máximo o impacto da prática desportiva como instrumento de política adequado para a sustentabilidade de um destino turístico.

Por último, importa referir que é necessário completar a presente análise com a verificação de indicadores cada vez mais objectivos que permitam avaliar de forma mais rigorosa a proposta teórica aqui apresentada.

No âmbito das Ciências do Desporto, teremos por exemplo os parâmetros fisiológicos, bem como da habilidades motoras necessárias para cada actividade específica para cada tipo de prática turístico desportiva.

Na perspectiva do TED é importante reunir a informação existente segundo a hipótese apresentada, nomeadamente no que diz respeito às diferentes tipologias de procura deste segmento.

Pela nossa parte, já foi desenhada uma experiência aplicada à actividade "Percursos Pedestres nas Termas de Monfortinho”, cujos resultados estão descritos noutro artigo dos mesmos autores ${ }^{6}$ Uma outra linha de investigação que importa de desenvolver tem a ver com a própria medição de impactos TPD como elemento potenciador da sustentabilidade dos destinos turísticos. 


\section{NOTAS}

1 Termo atribuído a Manuel Sérgio, significando "todo o movimento intencional do Homem na busca da superação dos seus limites e do sentido da vida".

2 Um espectáculo é uma representação pública que impressiona ou é destinada a impressionar. Pode ser uma apresentação teatral, musical, cinematográfica, circense, uma exibição de trabalhos artísticos etc. (0).

${ }_{3}$ Curiosamente não está consagrado na recente legislação portuguesa como tal; de entre os produtos que a lei consagra constam apenas o golfe e o turismo náutico. (Resolução Conselho Ministros 53/2007).

${ }_{4}$ A OMT utiliza o critério de permanência de pelo menos uma noite para definir turista, numa lógica exclusivamente quantitativa; no entanto, quando se analisa o fenómeno numa lógica global, temos que considerar que o visitante de um só dia é um elemento integrado dentro do fenómeno. Portanto, também o visitante turista desportivo é um elemento integrado dentro do fenómeno turismo desportivo. No âmbito do presente artigo passaremos a usar genericamente a expressão turista desportivo.

5 Não fazem distinção entre turismo de prática e de espectáculo desportivo, embora considerem a participação activa a passiva dentro da relação entre turismo e desporto.

${ }^{6}$ Lourenço e Carvalho (2008) Estudo de caso: Percursos Pedestres e os Termalistas clássicos em Monfortinho", Poster submetido para o Congresso APOGESD 2008, Porto.

\section{REFERÊNCIAS BIBLIOGRÁFICAS}

1. Confederação do Turismo Português/SaER (2005). Reinventando o Turismo em Portugal. Lisboa: Confederação do Turismo Português.

2. Cunha L (2003). Introdução ao Turismo. Lisboa: Edições Universitárias Lusófonas.

3. Cunha L (2003). Perspectivas e Tendências do Turismo. $2^{\text {a }}$ Ed. Lisboa: Editorial Verbo.

4. Gammon S, Robinson T (2003). Sport and Tourism: A Conceptual Framework. Journal of Sport Tourism 8(1): 2126.

5. Kurtzman J, Zauhar J (2003). A Wave in Time - The Sport Tourism Phenomena. Journal of Sport Tourism 8(1): 35-47.

6. Organización Mundial del Turismo (OMT) (1995). Conceptos, Definiciones y Classificaciones de las Estadisticas de turismo.

7. Pereira E (2006). Serviços de Desporto, Desporto e Turismo. Revista Portuguesa de Gestão do Desporto 3(1). APOGESD.

8. Pigeassou C, Bui-Xuan G, Gleyse J (2003). Epistemological Issues on Sport Tourism: Challenge for a New Scientific Field. Journal of Sport Tourism 8(1): 27-34.

9. Pigeassou C (2004). Contribution to the Definition of Sport Tourism. Journal of Sport Tourism 9(3): 287-289.

10. Pigeassou C (1997). Sport et tourisme: émergence du sport dans l'offre touristique, Entre passion et raison. Cahier Espaces 52 - Editions ESPACES Tourisme \& Loisirs.

11. Plagnol G (1997). Tourisme sportif et secteur marchand. Cahier Espaces 52 - Editions ESPACES Tourisme \& Loisirs.

12. Robinson T, Gammon S (2004). A question of primary and secondary motives: revisiting and applying the sport tourism framework. Journal of Sport Tourism 9(3): 221-233.

13. Secretaria de Estado da Juventude e do Desporto: www.sejd.gov.pt.

14. Sérgio M (1996). Epistemologia da Motricidade Humana. Lisboa: Faculdade de Motricidade Humana.

15. Standeven J, De Knop P (1998). Sport Tourism. Champaign (USA): Human Kinetics.

16. Wikipédia: pt.wikipedia.org

\section{CORRESPONDÊNCIA}

\section{Pedro Guedes de Carvalho}

E-mail: pguedes@ubi.pt

\section{Rui Lourenço}

E-mail: ruilour@gmail.com 